\title{
Carcinoma epidermóide causando grande destruição em mandíbula: relato de caso
}

\author{
Epidermoid carcinoma causing great destruction in the mandible: case report
}

Carcinoma de célula squamous causando gran destrucción en la mandíbula: un informe del caso

\author{
Thales Ramon Almeida Soares ${ }^{1 *}$, Isabela Fernandes Mamedes ${ }^{1}$, Aurea Valéria De Melo Franco ${ }^{1}$, \\ Fernanda Braga Peixoto ${ }^{1}$, Sonia Maria Soares Ferreira ${ }^{1}$.
}

\begin{abstract}
RESUMO
Objetivo: descrever as características clínicas, imaginológicas e histopatológicas do Carcinoma Epidermóide com extensa destruição óssea. Métodos: o caso clínico será descrito através da coleta de dados e as informações contidas no prontuário odontológico coligando aos exames do sujeito da pesquisa, após o consentimento do mesmo. Resultados: antes de iniciar o tratamento antineoplásico, é de extrema importância realizar a adequação do meio bucal do paciente para receber o tratamento radioterápico e quimioterápico proposto, afim de evitar possíveis complicações odontológicas durante as sessões, com finalidade de promover um maior conforto na qualidade de vida do paciente. Conclusão: o tratamento odontológico torna-se necessário antes das sessões de radioterapia e quimiotarapia. O Cirurgião-dentista possui um papel indispensável, contribuindo no diagnóstico assim como acompanhá-lo durante todo o tratamento antineoplásico, afim de evitar complicações orais que possam contribuir para uma piora na qualidade de vida do paciente.
\end{abstract}

Palavras-Chave: Neoplasias Bucais, Carcinoma, Doenças da Boca.

\begin{abstract}
Objective: to describe the clinical, imaging and histopathological features of Epidermoid Carcinoma with extensive bone destruction. Methods: The clinical case will be described through the collection of data and the information contained in the dental record by colándando to the examinations of the research subject, after the consent of the same. Results: before starting the antineoplastic treatment, it is extremely important to adjust the patient's oral environment to receive the proposed radiotherapy and chemotherapy, in order to avoid possible dental complications during the sessions, in order to promote greater comfort in the quality of life of the patient. Conclusion: dental treatment becomes necessary before radiotherapy and chemotherapy sessions. The dentist has an indispensable role, contributing to the diagnosis as well as accompanying him throughout the antineoplastic treatment, in order to avoid oral complications that may contribute to a worsening of the patient's quality of life.
\end{abstract}

Keywords: Mouth Neoplasms, Carcinoma, Mouth Diseases.

\section{RESUMEM}

Objetivo: describir las características clínicas, imaginológicas e histopatológicas del Carcinoma Epidermoide con extensa destrucción ósea. Métodos: el caso clínico será descrito a través de la recolección de datos y las informaciones contenidas en el pronóstico odontológico coligando a los exámenes del sujeto de la investigación, después del consentimiento del mismo. Resultados: antes de iniciar el tratamiento antineoplásico, es de extrema importancia realizar la adecuación del medio bucal del paciente para recibir el tratamiento radioterápico y quimioterápico propuesto, a fin de evitar posibles complicaciones odontológicas durante las sesiones, con el fin de promover un mayor confort en la calidad de vida del paciente. Conclusión: el tratamiento odontológico se hace necesario antes de las sesiones de radioterapia y quimioterapia. El Cirujano-dentista tiene un papel indispensable, contribuyendo en el diagnóstico así como acompañarlo durante todo el tratamiento antineoplásico, a fin de evitar complicaciones orales que puedan contribuir a un empeoramiento en la calidad de vida del paciente.

Palabras clave: Neoplasias de la boca, Carcinoma, Enfermedades de la boca.

${ }^{1}$ Centro Universitário Cesmac, Maceió-AL. * E-mail: almeidaasoares@hotmail.com 


\section{INTRODUÇÃO}

O carcinoma epidermóide de cabeça e pescoço, também conhecido como Carcinoma Espinocelular (CEC) é um dos tipos de câncer mais frequente no mundo, chegando a representar mais de $90 \%$ dos tumores malignos que envolvem a cavidade oral (MENDONÇA et al., 2015). A faixa etária de maior acometimento para o aparecimento do CEC inicia-se entre 50 e 60 anos de idade, sendo mais frequente no gênero masculino (VALLE et al., 2016; MAMANI et al., 2017). Assoalho bucal e língua são localizações mais comuns para o aparecimento do carcinoma (BITTAR et al., 2015; TUSTUMI et al., 2016), porém, quando há invasão do tumor em estruturas ósseas, é classificada como T4, implicando em um mau prognóstico (LI et al., 2017).

Sua etiologia está associada à vários fatores: deficiência nutritiva, exposição à radiação solar, imunosupressão, tabaco, álcool e infecção por HPV (NEVILLE et al., 2009; TUSTUMI et al., 2016). Destes, os que mais se destacam é o consumo excessivo de álcool e tabagismo, que quando associados, aumentam significativamente seu poder de malignidade, levando em consideração o tempo que se fuma, o número de cigarros fumados ao dia e a frequência de ingestão de álcool. Na fumaça expelida no ato de fumar já foram identificadas mais de 5.300 substâncias, e em média 70 delas são carcinógenos (ALMEIDA et al., 2014).

Clinicamente, em sua fase inicial é comum o aparecimento de lesão ulcerada persistente que pode ou não estar acompanhada de mancha branca, vermelha ou eritematosa, com bordas irregulares e que sangra com facilidade (MAMANI et al., 2017; SILVA e DIAS, 2017).

Radiografias são exames auxiliares para avaliar a invasão e extensão das lesões ósseas. No estágio inicial da doença, os exames radiográficos, como a radiografia panorâmica, vai contribuir, se já houver comprometimento ósseo da lesão (OHTAKE et al., 1989). Em estágios mais avançados da doença deve ser feito com base em exames de imagens conjugadas, radiografias com a tomografia computadorizada (TC) (FRIEDMAN et al., 1993; FAGELMAN e HUANG, 1994). A TC oferece cortes que possibilitam a interpretação das alterações resultantes de doenças malignas da cavidade oral, proporcionando identificar o grau de infiltração do tumor e envolvimento das corticais ósseas.

No exame histopatológico pode-se observar um epitélio de superfície displásico, caracterizado por ilhas e cordões invasivos de células escamosas epiteliais malignas (NEVILLE et al., 2009; CHI et al., 2015). Quanto menor a diferenciação histológica, maior é o grau de malignidade da lesão (SILVA e DIAS, 2017).

O tratamento a ser realizado será definido através do sistema de estadiamento TNM. Esse sistema classifica os tumores de acordo com tamanho ( $\mathrm{T}$ ), comprometimento dos linfonodos (N) e presença de metástase (M) (NEVILLE et al., 2009; VIEIRA et al., 2012). O principal tratamento para esta doença, é a combinação de cirurgia, radioterapia e quimiotarapia, que devem ser combinadas de acordo com o prognóstico (LI et al., 2017).

A indicação do tratamento a base de quimioterapia, costuma ser uma escolha paliativa, não objetivando a cura do paciente (CALDAS JÚNIOR et al., 2015). Sobretudo, ainda não existe o melhor tratamento e nem um específico para o câncer de cavidade oral (DANIEL et al., 2006; REGEZI et al., 2008; VALLE et al., 2016).

Para conseguir um resultado antineoplásico satisfatório, o tratamento odontológico torna-se fundamental e necessário antes das sessões programadas de radioterapia e quimiotarapia, evitando as interrupções e melhorando a qualidade de vida do indivíduo (SANTOS et al., 2010).

Efeitos colaterais como a osteorradionecrose, por exemplo, é um dos problemas causado pela radiação, que proporciona efeitos deletérios nos osteoblastos, osteócitos e células endoteliais, reduzindo a capacidade do osso em se recompor de uma lesão. É necessário instruir o paciente sobre a importância de manter uma higiene bucal minuciosa, que é essencial para diminuir riscos de taxas aumentadas de cáries dentárias nos pacientes com xerostomia e osteorradionecrose da mandíbula após o tratamento radioterápico (MOMARES et al., 2014; ÁVILA et al., 2016).

O Cirurgião-dentista possui um papel imprescindível junto ao paciente com CEC, contribuindo no diagnóstico, adequação do meio bucal e acompanhamento durante o tratamento proposto afim de evitar 
complicações orais que contribuam para uma piora na qualidade de vida do paciente (MENDONÇA et al., 2015; VALLE et al., 2016).

Tendo em vista a relevância para o conhecimento dos profissionais da área de saúde, o objetivo deste trabalho foi descrever as características clínicas, imaginológicas e histopatológica do Carcinoma Epidermóide com extensa destruição óssea.

\section{RELATO DO CASO}

Paciente do gênero masculino, feoderma, cinquenta e seis anos de idade, compareceu ao serviço de Estomatologia do PAM Salgadinho com lesão no lado direito da mandíbula. Na queixa principal, o paciente relatou sentir "dor e inchaço". Na história da doença atual o mesmo relatou que há aproximadamente 2 meses do primeiro dia da consulta, começou a sentir um aumento de volume na região de mandíbula direita, que evoluiu de forma rápida e acompanhada com muita sintomatologia dolorosa. Quando questionado sobre a história médica, relatou não ser portador de nenhuma doença sistêmica, mas afirmou ter tido tuberculose há mais de vinte anos. O mesmo afirma ser fumante e etilista há 38 anos.

Ao exame físico extrabucal, observou-se uma tumoração endurecida do lado direito mandibular com assimetria facial (Figura 1 A e B).

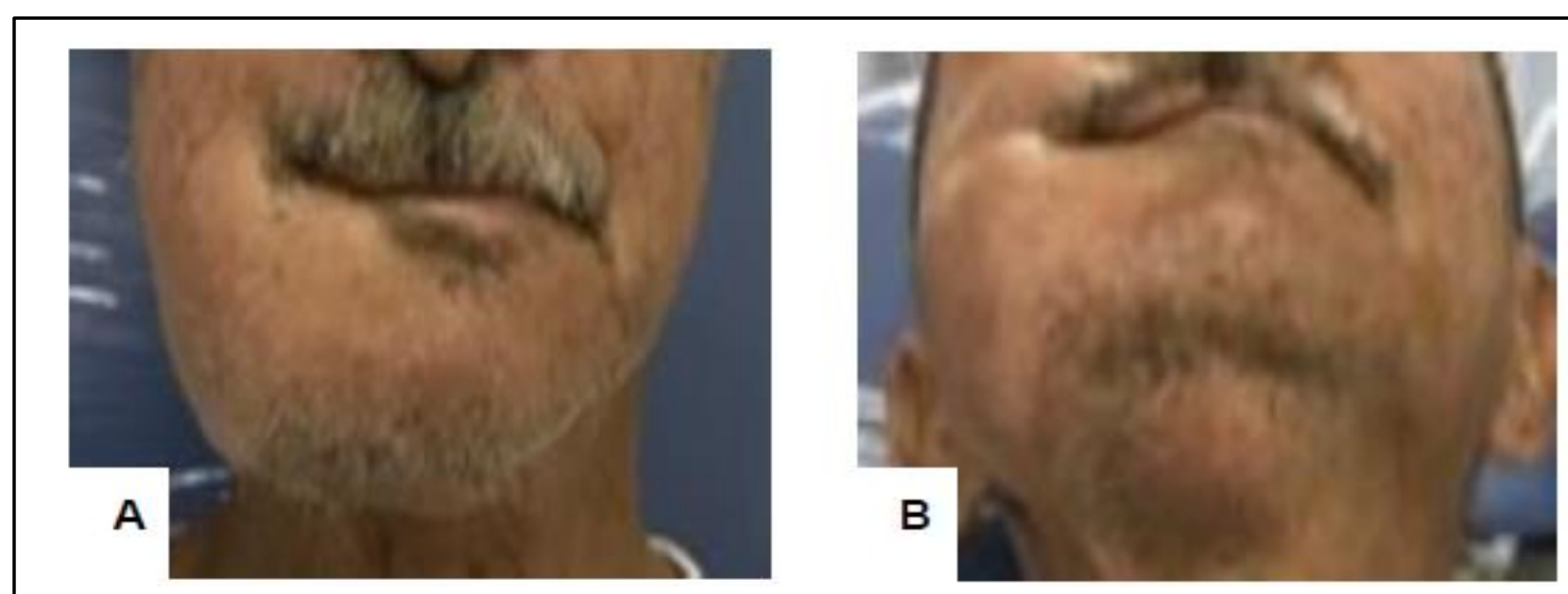

Figura 1: A. Vista frontal - Assimetria facial; B. Vista frontal - Nódulo endurecido. Fonte: Arquivo Cesmac.

No exame físico intrabucal, foi observada a presença de uma extensa lesão localizada no rebordo alveolar na região direita de mandíbula, com bordas endurecidas, ulceradas e fundo necrótico. Paciente relatou sentir dor expontânea. (Figura 2 ).

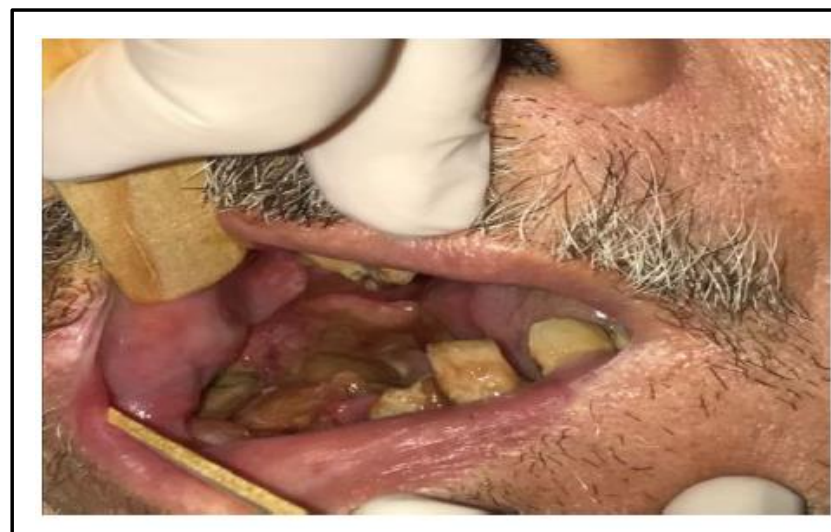

Figura 2. Lesão ulcerada no rebordo alveolar. Fonte: Arquivo Cesmac. 
Foi realizada biópsia incisional e a peça foi encaminhada para o laboratório de patologia bucal do Centro Universitário Cesmac com diagnóstico de Carcinoma de Células Escamosas (CEC). O paciente foi encaminhado para Extensão de Oncologia do Centro Universitário Cesmac para adequação do meio e iniciar o tratamento proposto pelo oncologista.

Na radiografia panorâmica é possível observar no lado direito, extensa lesão agressiva radiolúcida. Em um sentido, a lesão se estende da região do dente 43 a região do dente 48 , e em outro sentido causa total destruição das bordas anterior e inferior da mandíbula, com dentes flutuando e seqüestros ósseos. Houve destruição das corticais do canal mandíbular e cortical óssea mandibular com fratura patológica em região da base mandibular (Figura 3).

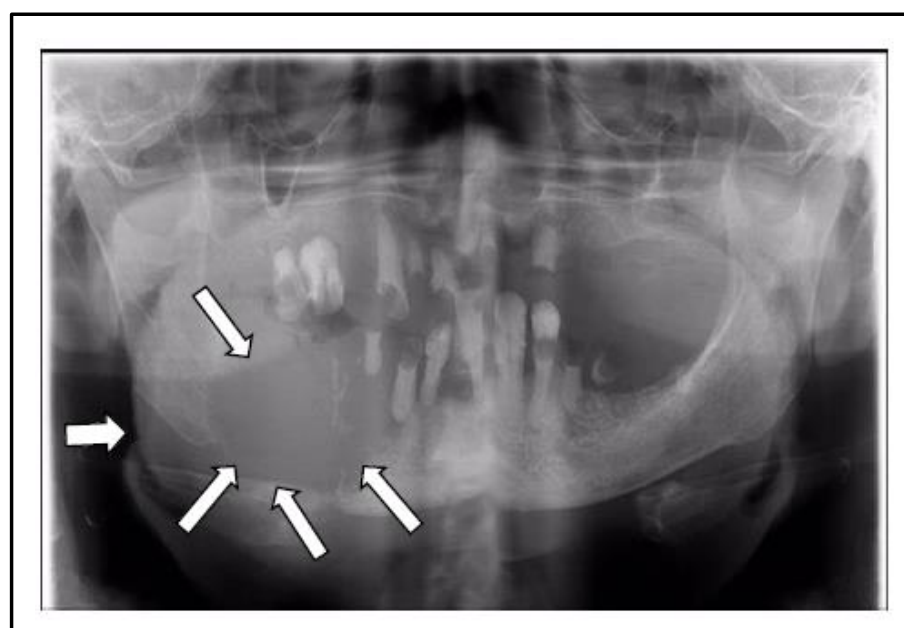

Figura 3. Radiografia panorâmica inicial apresentando extensa lesão osteolítica com fratura na base mandibular, dentes flutuando na tumoração. Fonte: Arquivo Cesmac.

Os cortes histológicos revelaram fragmentos de neoplasia maligna de origem epitelial. Ilhas de células neoplásicas invadiam e destruíam o tecido conjuntivo subjacente. Atipias celulares como, por exemplo, pleomorfismo celular e nuclear e mitoses atípicas estavam presentes. Intenso infiltrado inflamatório crônico completava o quadro microscópico, chegando ao diagnóstico definitivo de Carcinoma de Células Escamosas (CEC) (Figura 4).

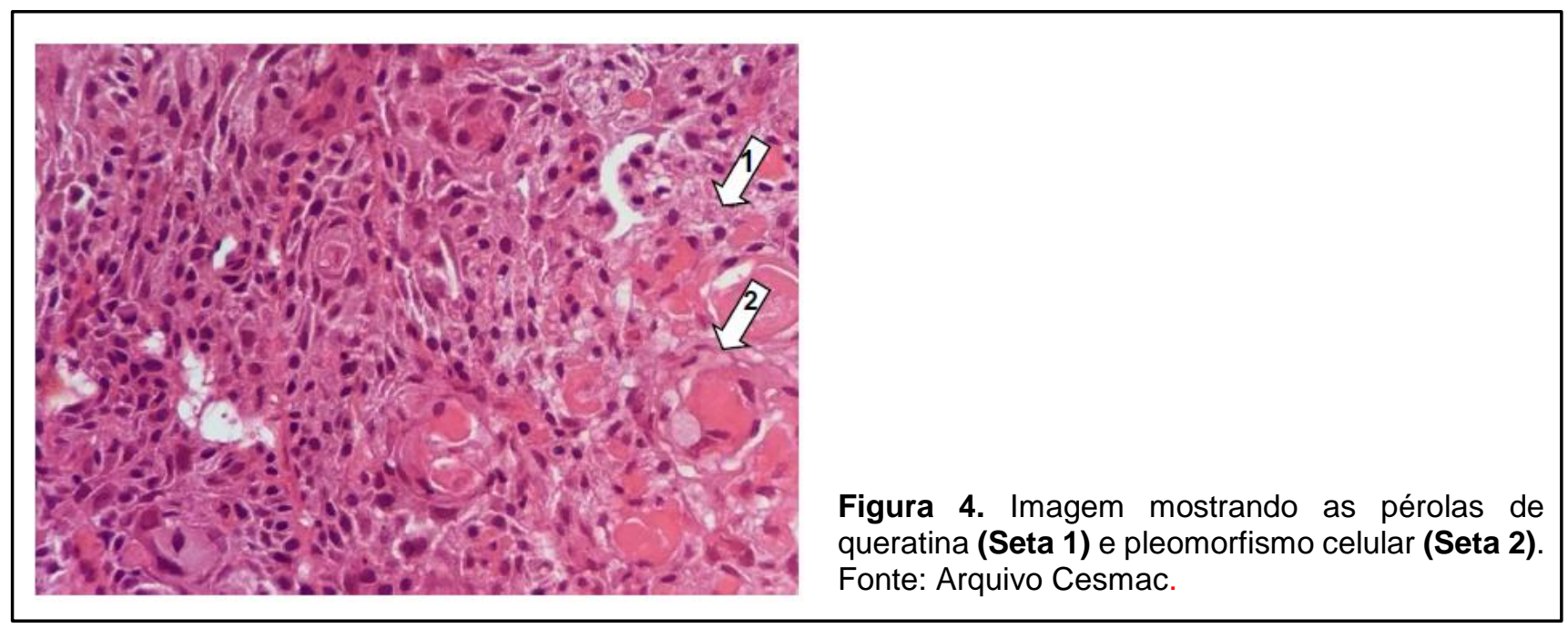


Tendo em vista a condição bucal do paciente com cáries extensas e doença periodontal avançada, foram indicadas as extrações de todos os dentes e restos radiculares (Figura 5 A e B).

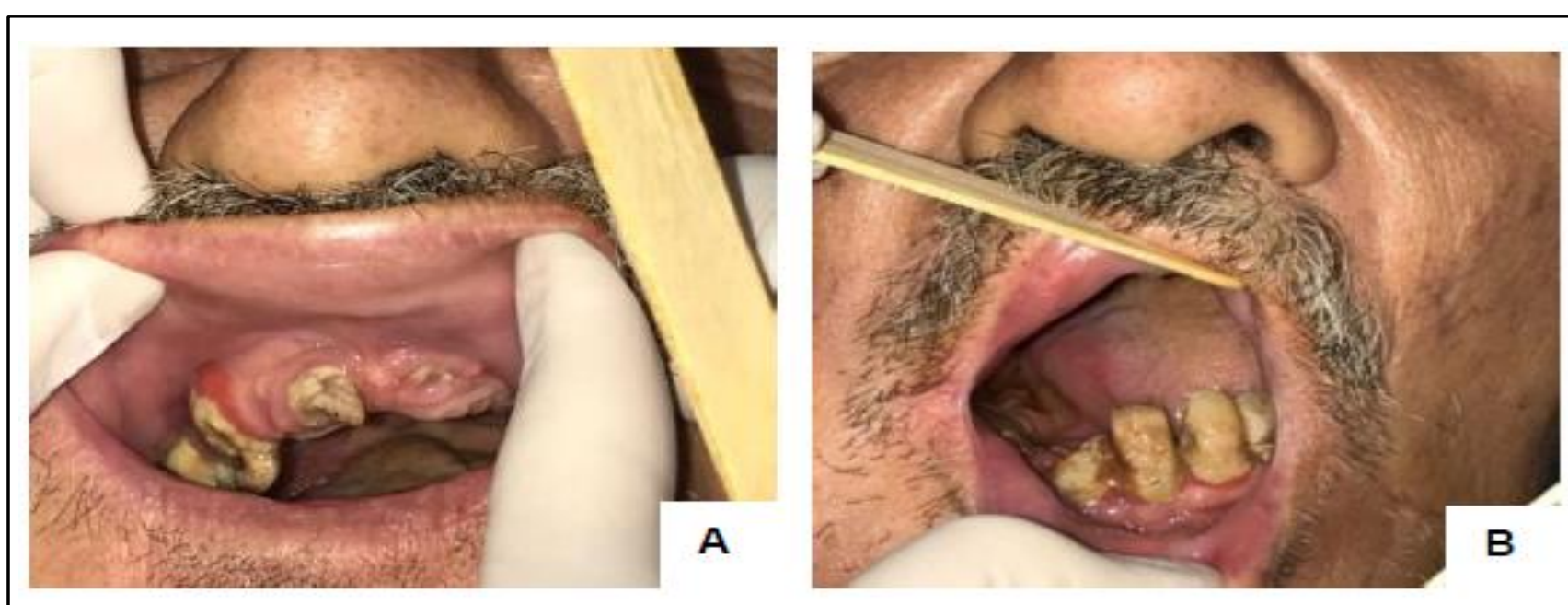

Figura 5: A e B. Condição bucal do paciente com dentes cariados, restos radiculares e doença periodontal. Fonte: Arquivo Cesmac.

A cirurgia para remoção dos dentes foi realizada em duas etapas. Inicialmente a exodontia de todos os dentes e restos radiculares superiores (Figura 6 A e B) e após sete dias a extração dos dentes e restos radiculares inferiores (Figura 7 A e B).

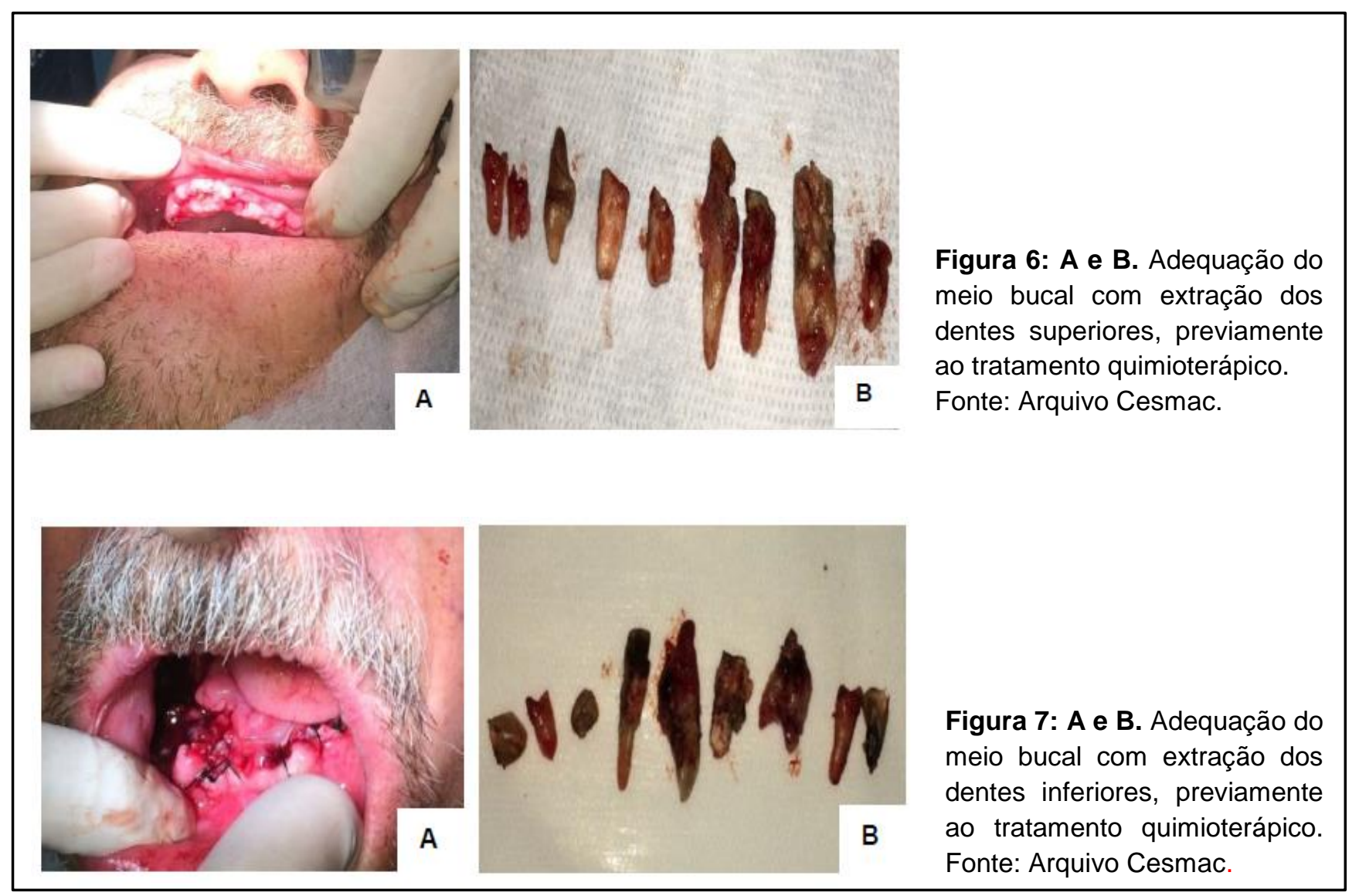


O tratamento proposto foi de quimioterapia e radioterapia no hospital Santa Casa de Misericórdia de Maceió apresentando convênio pelo Sistema Único de Saúde (SUS). Foi solicitado pelos oncologistas exames de hemograma completo e tomografia do tórax, para avaliar o quadro clínico sistêmico do paciente, além do auxílio da nutricionista para mudança dos hábitos alimentares.

De acordo com o planejamento, iniciou-se a quimioterapia induzida, onde o paciente foi submetido a internação durante cinco dias seguidos, no qual cada internação corresponde a uma sessão, sendo realizada cinco sessões totais. A partir da segunda sessão quimioterápica a lesão diminuiu de volume, porém o paciente apresentou trismo e ressecamento epidérmico como efeitos colaterais (Figura 8 A e B).
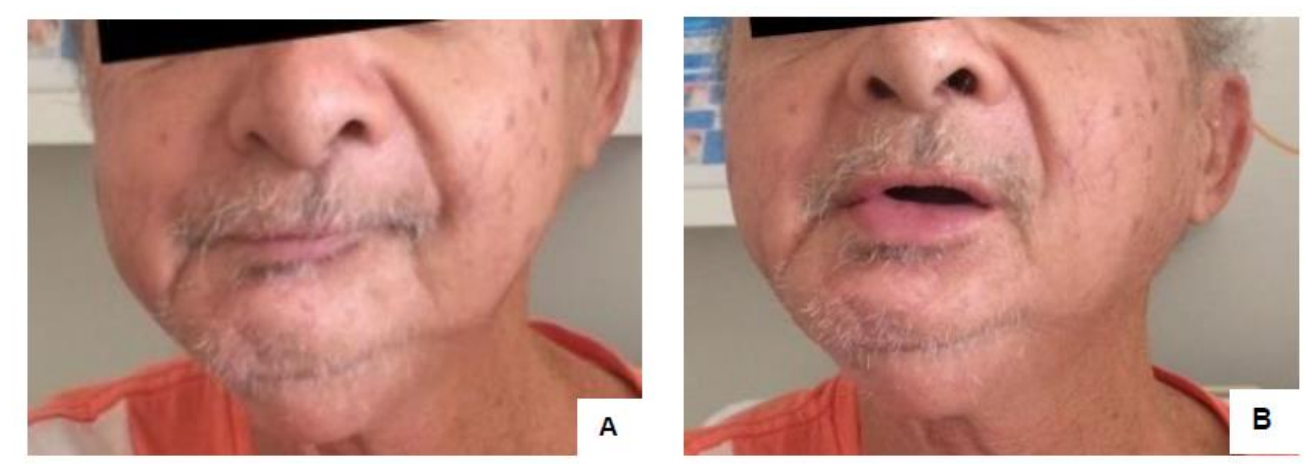

Figura 8: A. Resultado após a segunda sessão de quimioterapia. B. Máxima abertura da boca -Trismo. Fonte: Arquivo Cesmac.

A tomografia computadorizada por feixe cônico da mandíbula (imagem axial de referência) (Figura 9 A), reconstrução panorâmica (Figura 9 B) e corte axial (Figura 9 C), mostra extensa destruição óssea no corpo da mandíbula, no lado direito, estendendo-se até a basilar mandibular com fratura patológica.

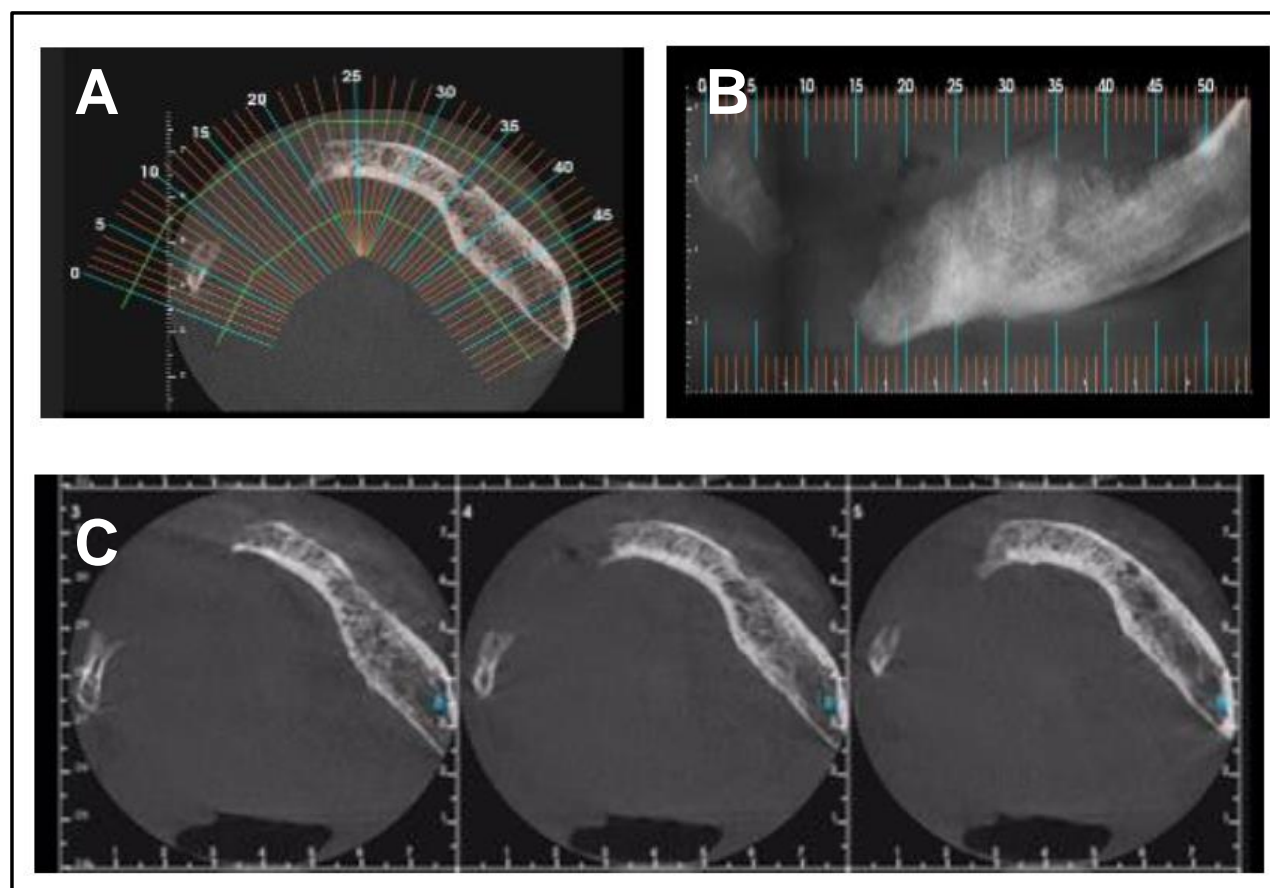

Figura 9: Tomografia computadorizada cone beam. Aquisição de corte axial. (A) Exame pós cirúrgico da mandíbula. (B) Extensa destruição óssea no corpo da mandíbula, com fratura e separação de fragmento. (C) Reconstrução axial mostra destruição óssea no corpo da mandíbula, com fratura e separação de fragmentos.

Fonte: Arquivo Cesmac. 
Para o tratamento radioterápico, a opção de escolha foi a radioterapia conformacional. Foi realizada a confeccão de uma máscara onde a irradiação se propagará apenas nos pontos de referência da máscara, envolvendo toda cavidade oral, pescoço e clavícula bilateral. As sessões serão realizadas diariamente de segunda à sexta, durante um mês e meio de tratamento. Alguns possíveis efeitos colaterais podem ocorrer durante essa fase e foram esclarecidos ao paciente, sendo os principais deles a radiodermite, mucosite, disfagia, disfonia, xerostomia, perda do paladar, mielite e osteorradionecrose. Foi instruído ao paciente todos os cuidados e orientações necessárias de higiene oral para que os melhores resultados sejam alcançados.

Foi iniciado o tratamento radioterápico, no entanto as complicações que o Carcinoma Epidermóide causou no paciente, impossibilitou o mesmo a dar continuidade à radioterapia. Fez apenas seis sessões, mas não conseguiu finalizar o tratamento, chegando a óbito.

\section{DISCUSSÃO}

O Carcinoma Epidermóide (CEC) mostra ser mais prevalente no sexo masculino, entre 50 e 60 anos de idade, tendo como local de predileção região de língua e assoalho bucal. Sua origem é multifatorial, podendo ser fatores extrínsecos que são a fumaça, álcool, sífilis e luz solar, e fatores intrínsecos incluem desnutrição geral ou anemia por deficiência de ferro (MAMANI et al., 2017). Mendonça et al. (2015), confirma a opnião de Mamani et al. (2017) em relação aos fatores predisponentes que contribuem para o desenvolvimento da malignidade do carcinoma epidérmoide, dando ênfase aos usuários de tabaco e álcool (MENDONÇA et al., 2015; MAMANI et al., 2017), porém possuem opiniões divergentes relacionado a faixa etária do indivíduo, onde Mendonça et al. (2015) cita que o CEC possui predominância entre a sexta e a sétima década de vida (MAMANI et al., 2017). No caso relatado o paciente é do sexo masculino, 56 anos de idade e usuário de álcool e tabaco desde os 18 anos de idade, sendo esse um dos fatores que potencializam o risco de câncer. Alvarenga et al. (2008), citado por Mamani et al. (2017), argumenta que a maioria dos indivíduos foram do sexo masculino (86\%), realizavam atividades rurais e no sexo feminino realizavam atividades domésticas, em relação ao consumo de cigarro e álcool, $83,7 \%$ eram tabagistas, $65,8 \%$ eram etilistas, $55,27 \%$ possuíam os dois hábitos e apenas $6,18 \%$ não possuíam nenhum desses hábitos (MAMANI et al., 2017). No caso clínico descrito, foi encontrado uma neoplasia maligna em região de rebordo alveolar, diferente do estudo encontrado na literatura pesquisada (MAMANI et al., 2017). Quanto a idade, gênero e etiologia, houve concordância entre o relato do caso clínico e os autores Mamani (2017) e Tustumi (2016).

Segundo Mendonça et al. (2015), a fase inicial apresenta-se com uma dor mínima, motivo que leva o indivíduo a procurar ajuda profissional tardia. Clinicamente, a lesão pode se manifestar de forma exofítica (quando seu crescimento ocorre de dentro para fora) ou endofítica (ocorrendo de fora para dentro), e ainda, pode ou não estar acompanhada de manchas leucoplásicas, eritroplásicas ou eritroleucoplásicas afirmando que os tipos leucoplásicos e eritroplásicos nas fases iniciais, tem características iguais as lesões prémalignas, podendo levar a um diagnóstico errado se não houver a realização e confirmação da biópsia (MENDONÇA et al., 2015). Silva e Dias (2017) afirma que a lesão é caracterizada por uma mancha persistente, com bordas vermelhas e que sangra com facilidade (SILVA e DIAS, 2017), Mamani (2017) ainda complementa que os tumores avançados apresentam tecido necrótico, bordas elevadas e consistência endurecida (MAMANI et al., 2017; SILVA e DIAS, 2017). No presente estudo, as características clínicas foram compatíveis com as mesmas descritas por Mendonça (2015), Mamani (2017), Silva e Dias (2017), demonstrando total concordância entre eles.

Os exames de imagens servem de parâmetro para avaliação do comprometimento entre a lesão e o tecido ósseo (OHTAKE et al., 1989). Chi et al. (2015) destaca a importância de solicitar exames de imagens adicionais para verificar presença ou ausência de metástases á distância, bem como Friedman et al. (1993), Fagelman e Huang (1994) asseguraram que exames de imagens conjugadas, como a tomografia computadorizada, por exemplo, são essenciais e indispensáveis nos estágios avançados da doença, proporcionando identificar o grau de infiltração do tumor (FRIEDMAN et al., 1993; FAGELMAN e HUANG, 1994). No caso relatado, foi realizada inicialmente, radiografia panorâmica para visualizar a extensão e localização da lesão e complementado com exame de tomografia computadorizada para avaliar a 
tridimensionalidade do Carcinoma Epidermóide. No referido relato de caso, a tomografia mostrou extensa destruição óssea no lado direito do corpo da mandíbula.

As características histopatológicas de acordo com Neville et al. (2009) e Silva e Dias (2017), foi possível observar um epitélio de superfície displásico, caracterizado por ilhas e cordões invasivos de células escamosas epiteliais malignas (NEVILLE et al., 2009). Quanto menor a diferenciação histológica, maior é o grau de malignidade da lesão (SILVA e DIAS, 2017). Comparando a literatura com o caso proposto obteve concordância relacionado a revelação de fragmentos de neoplasia maligna de origem epitelial e ilhas de células neoplásicas que invadiram e destruíram o tecido conjuntivo subjacente.

Daniel et al. (2006) comenta que radioterapia e a quimioterapia produzem danos nas células com alta taxa de divisão. Portanto, a mucosa oral vira alvo principal da toxicidade devido sua alta taxa de renovação celular sendo capazes de deixarem sequelas temporárias e até mesmo permanentes, sendo agravados caso não seja feita uma adequação do meio bucal (DANIEL et al., 2006). Caldas Júnior et al. (2015) e Regezi et al. (2008) discutem que é muito comum o aparecimento de danos temporários, como por exemplo, mucosite, dor local, alterações no paladar, candidíase e dermatite, sendo efeitos colaterais ligado a radioterapia. Como efeitos colaterais permanentes, inclui-se o aparecimento de xerostomia, cárie cervical, trismo e osteorradionecrose (CALDAS JÚNIOR et al., 2015; REGEZI et al., 2008). De acordo com Caldas Júnior et al. (2015), alguns pacientes necessitam de extrações dentárias que deverão ser realizadas antes do tratamento radioterápico, havendo uma possível prevenção de efeitos indesejáveis, favorecendo ao paciente alívio dos sintomas e evitando maiores danos (CALDAS JÚNIOR et al., 2015). De acordo com a condição bucal do paciente relatado, cáries extensas e doença periodontal avançada poderam ser observadas e foram indicadas as extrações de todos os dentes e restos radiculares, dando continuidade ao tratamento de quimioterapia e radioterapia, levando o mesmo a apresentar trismo e ressecamento epidérmico como efeitos colaterais. Apesar disso, houve diminuição de volume da lesão desde a segunda sessão quimioterápica.

Ávila et al. (2016) e Momares et al. (2014), afirmam que apesar dos avanços de métodos terapêuticos e na compreensão dos mecanismos moleculares envolvidos na patogênese do carcinoma, as taxas de sobrevida tem permanecido estáveis em 5 anos, com valores entre $48 \%$ e 61,5\%. Ele ainda afirma que o tempo de sobrevida, depende diretamente da localização do tumor, do estadiamento, assim como o método de tratamento instituído (MOMARES et al., 2014; ÁVILA et al., 2016). No caso relatado, o paciente realizou cinco sessões de quimioterapia, sendo submetido a internação durante cinco dias seguidos. Cada internação correspondeu a uma sessão, sendo realizada cinco sessões totais já concluídas. Foram realizadas sessões radioterápicas, de segunda à sexta, até completarem as 35 sessões totais programadas. Até o presente momento, já foram executadas seis sessões diariamente, sendo conjugada com uma sessão de quimioterapia por semana. Ao decorrer das sessões, houve diminuição do tamanho da lesão, mas o paciente apresentou efeitos colaterais.

As complicações que o Carcinoma Epidermóide causou no paciente, provocou trismo, mucosite e ressecamento epidérmico como efeitos colaterais. Além do mesmo ser fumante e etilista há 38 anos e apresentar idade superior a 50 anos referente a taxa de mortalidade presente em pacientes com CEC, impediu o mesmo a dar continuidade à radioterapia e a quimioterapia. Fez apenas seis sessões radioterápicas, mas não conseguiu concluir o tratamento, chegando a óbito.

\section{CONSIDERAÇÕES FINAIS}

Dessa maneira, para obter um resultado antineoplásico satisfatório, o tratamento odontológico torna-se essencial e necessário antes das sessões programadas de radioterapia e quimiotarapia, evitando as interrupções e melhorando a qualidade de vida do indivíduo. Informar o paciente sobre a importância de manter uma higiene bucal apropriada, é fundamental para diminuir os riscos de cáries dentárias em pacientes com xerostomia e osteorradionecrose da mandíbula após o tratamento radioterápico. O Cirurgião-dentista possui um papel imprescindível contribuindo no diagnóstico, fazendo adequação do meio bucal e acompanhando o paciente com CEC durante todo o tratamento proposto, afim de evitar complicações orais que possam contribuir para uma piora na qualidade de vida do indivíduo. 


\section{REFERÊNCIAS}

1. ALMEIDA AA, BANDEIRA CM, GONÇALVES AJ, et al. Dependência nicotínica e perfil tabágico em pacientes com câncer de cabeça e pescoço. Revista Jornal Brasileiro de Pneumologia, 2014; 40(3): 286-293.

2. ÁVILA MF, JARA MD, RONDANELLI BM. Carcinoma espinocelular de lengua: estúdio de sobrevida a 5 años. Revista Clínica de Periodontia, Implantogia e Reabilitação Oral, 2016; 9(1): 74-78.

3. BITTAR RF, FERRARO HP, RIBAS MH, et al. Predictive factors of occult neck metastasis in patients with oral squamous cell carcinoma. Revista Elsevier Editora Ltda, Brasil. São Paulo, 2016; 82(5): 543-547.

4. CALDAS JÚNIOR A, BARBOSA A, TETI IM, et al. Alterações bucais em pacientes submetidos ao tratamento quimioterápico de câncer na rede pública de Recife-PE. Ciências Biológicas e da Saúde, 2015; 2(2): 37-46.

5. CHI AC, DAY TA, NEVILLE BW. Oral Cavity and Oropharyngeal Squamous Cell Carcinoma - An Update. Revista Ca: Cancer J Clin, 2015; 65(5): 401-421.

6. DANIEL FI, GRANATO R, GRANDO LJ, et al. Carcinoma de células escamosas em rebordo alveolar inferior: diagnóstico e tratamento odontológico de suporte. J Bras Patol Med Lab, 2006; 42(4): 279-283.

7. FAGELMAN D, HUANG AB. Prospective evaluations of lesion of the mandible and maxilla: findings on multiplanar and three-dimensional CT. AJR Am J Roentgenol, 1994; 163(3): 693-698.

8. FRIEDMAN M, MAFEE M, RAY C, et al. Three dimensional imaging for evaluation of head and neck tumors. Revista Arquivos de Otorrinolaringologia - Cirurgia de Cabeça e Pescoço, 1993; 119(6): 601-607.

9. LI C, LIN J, MEN Y, et al. Does Medullary Versus Cortical Invasion of the Mandible Affect Prognosis in Patients With Oral Squamous Cell Carcinoma?. J Oral Maxillofac Surg, 2017; 75(2): 403-415.

10. MAMANI MP, CALDANA ML, BASTOS RS, et al. Neoplasias bucais em indivíduos idosos no Brasil: Revisão integrativa. Revista Rede de Cuidados em Saúde, 2017; 10(1): 1-18.

11. MENDONÇA JCG, MELO RL, BARROS RMG, et al. Carcinoma epidermóide lingual com esvaziamento cervical unilateral supra-omohioideo: relato de caso. Revista Arquivos de Investigação em Saúde, 2015; 4(6): 31-36.

12. MOMARES B, CONTRERAS G, MARTÍNEZ B, et al. Sobrevida en carcinoma espinocelular de mucosa oral: análisis de 161 pacientes. Revista Chilena de Cirurgia, 2014; 66(6): 568-576.

13. NEVILLE BW, DAMM DD, ALLEN CM, et al. Patologia Oral e Maxilofacial. 3nd ed. Rio de Janeiro: Elsevier, 2009; 410p.

14. OHTAKE K, YOKOBAYASHI Y, SHINGAKI S, et al. Central Carcinoma of the jaw. A survey of 28 cases in the Japanese literature. Revista Jornal de Cirurgia Craniomaxilofacial, 1989; 17(4): 155-161.

15. REGEZI JA, SCIUBBA JJ, JORDAN RCK, et al. Patologia Oral: correlações clinicopatológicas. 5nd ed. Rio de Janeiro: Elsevier, 2008; 48p.

16. SANTOS LCO, BATISTA OM, CANGUSSU MCT. Caracterização do diagnostico tardio do câncer de boca no estado de Alagoas. Revista Brasileira de Otorrinolaringologia, 2010; 76(4): 416-422.

17. SILVA RD, DIAS MAI. Incidência do carcinoma basocelular e espinocelular em usuários atendidos em um hospital do câncer. Revista Família: Ciclos de Vida e Saúde no Contexto Social, 2017; 5(2): 228-234.

18. TUSTUMI F, TAKEDA FR, KIMURA CMS, et al. Esophageal Carcinoma: is squamous cell carcinoma different disease compared to adenocarcinoma? A transversal study in a quaternary high volume hospital in Brazil. Revista Arquivos de Gastroenterologia, 2016; 53(1): 44-48.

19. VALLE CN, PASSOS RMM, GONÇALVES JTCL, Gomes C, et al. Carcinoma Espinocelular Oral: um panorama atual. Revista de Patologia do Tocantins, 2016; 3(4): 82-102.

20. VIEIRA R, MINICUCCI EM, MARQUES MEA, et al. Acnitic cheilitis and squamous cell carcinoma of the lip: clinical, histopathological and immunogenetic asects. Revista Anais Brasileiros de Dermatologia, 2012; 87(1): 105-114. 